\title{
Histological studies of the effects of chronic administration of chloroquine on the inferior colliculus of the adult wistar rat
}

\author{
JO Adjene $e^{1}$ and TK Adenowo ${ }^{2}$
}

\begin{abstract}
The effects of chronic administration of chloroquine commonly used for prophylaxis or treatment of malaria, rheumatoid arthritis and lupus erythematosis on the inferior colliculus (IC) of adult male and female wistar rats was studied. Seventeen rats of average weight $184 \mathrm{~g}$ were randomly assigned into treatment $(\mathrm{n}=10)$ and control $(\mathrm{n}=$ 7) groups. Rats in the treatment group received $2 \mathrm{mg} / \mathrm{kg}$ body weight of chloroquine phosphate dissolved in distilled water daily for 14 days. The control rats received equal volume of distilled water daily. The rats were fed with rat pellets purchased from Ladokun Feeds Limited, Ibadan, Nigeria and given water liberally. They were then sacrificed on day fifteen of the experiment. The inferior colliculus was carefully dissected out and quickly fixed in $10 \%$ formal saline for histological study. Findings indicate that rat in the treated group showed degenerative changes, vacuolations and reduced cellular population in the inferior colliculus. Chronic administration of chloroquine has adverse effect on the micro-anatomy of the inferior colliculus in rats. Chloroquine may have adverse effects on the auditory sensibilities by affecting the micro-anatomy of the inferior colliculus of the adult wistar rats. We recommended further studies aimed at corroborating these observations.
\end{abstract}

\section{INTRODUCTION}

Chloroquine is a commonly used antimalarial drug that belongs to the quinolone family. It is usually given for malaria prophylaxis and treatment but also used by rheumatologists for treating rheumatoid arthritis, systemic/ discoid lupus erythematosis and other

KEY WORDS: Chloroquine, histology, rats, hearing

${ }^{1}$ Department of Anatomy, School of Basic Medical Sciences, University of Benin, Benin City, Nigeria. E-mail: joadjene@yahoo.com; Tel: 2348034084016. ${ }^{2}$ Department of Anatomy and Cell Biology, Obafemi Awolowo University, Ile-Ife, Nigeria. Tel: 2348033539613

(C) CMS UNIBEN JMBR 2005; 4(1): 83-87 connective tissue disorders. ${ }^{1}$ In malaria endemic areas like Africa, chloroquine has been greatly misused especially in cases of self-medication. Self-medication and drug misuse is on the increase in Nigeria due to prevailing economic conditions and deteriorating health care delivery systems. A more recent indication for chronic administration of chloroquine is in the prophylaxis of malaria, for which the drug is administered at a dosage of $300-600 \mathrm{mg}$ weekly to adults. ${ }^{2}$

Chloroquine crosses the blood-brain barrier and has been reported to accumulate in the brain and other tissues. ${ }^{2}$ Its intoxication leads to an increase in gangliosides in the 
nervous system with the largest effect in the dorsal root ganglion and retina as reported in pigs, $^{3}$ rats $^{4}$ and rhesus monkey. ${ }^{5}$

Evidence from research has shown that some patients with retinopathy may be asymptomatic following chloroquine treatment. When they are asymptomatic, visual acuity initially remains excellent despite complaints of parafoveal metamorphopsia and difficulty in reading or performing fine visual task due to central or paracentral scotomas. Rarely, neurologic symptoms such as vertigo, tinnitus, irritability, cranial nerve palsies and myasthenialike muscle weakness may also manifest following chloroquine treatment. ${ }^{1}$

The effects of chloroquine on the intracranial auditory pathway seem not to have been well documented. The inferior colliculus is the obligatory midbrain synaptic target of the ascending auditory pathway in which the contralateral ear is represented primarily. ${ }^{6}$ Inferior colliculus is essential for normal hearing and for the startle reflex. It receives its ascending input mainly from the contralateral cochlear nucleus and the superior olive, and sends axons to the medial geniculate body. ${ }^{6}$ Reports indicate that glucose consumption of the whole rat brain is twice that of human brain (about $0.27 \mu \mathrm{moles} / \mathrm{g} / \mathrm{min}),{ }^{7}$ while glucose consumption in rat cerebral cortex is about three times that of human brain. Thus, there is an inverse relationship between cerebral metabolic rate and body size. Cortical structures such as the medial and lateral geniculate bodies, inferior and superior colliculi have higher glucose utilisation than other structures. ${ }^{7}$ There is also correlation between functional activity and metabolic rate such as in the visual and auditory systems. ${ }^{7}$

Tissue enzymatic activities prove reliable for interpretation purposes since they condition the rate of cerebral biochemical reactions in which modifications in substrate intermediates and end products represent the effect of their action. ${ }^{8}$ Since chloroquine crosses the blood-brain barrier, it is relevant to investigate its effect on the intracranial auditory relay centres. The adverse effects of chloroquine on hearing, such as tinnitus, may be due to the direct effect of chloroquine on auditory relay centres.

\section{MATERIALS AND METHODS}

\section{Animals}

Seventeen male and female adult wistar rats weighing 180-200g were randomly assigned into two groups, the control $(\mathrm{n}=7)$ and treated $(n=10)$ groups. The rats were maintained in the animal holdings of the Department of Anatomy and Cell Biology, Obefemi Awolowo University, Ile-Ife, Osun State, Nigeria. They were fed with rat pellets purchased from Ladokun Feeds Limited, Ibadan, Nigeria, and given water liberally. Chloroquine phosphate tablets were obtained from the Department of Pharmaceutical Chemistry, Faculty of Pharmacy, Obafemi Awolowo University, IleIfe.

\section{Drug administration}

Rats in the treatment group received $2 \mathrm{mg} / \mathrm{kg}$ body weight of chloroquine phosphate dissolved in distilled water for 14 days. Rats in the control group received equal volume of distilled water using orogastric tube. The rats were sacrificed by cervical dislocation on the 15th day. Their skulls were opened using bone forceps to expose the brain. The inferior colliculus was quickly dissected out and fixed in $10 \%$ formal saline for routine histological techniques.

\section{Histological study}

The tissues were dehydrated in an ascending grade of alcohol (ethanol), cleared in xylene and embedded in paraffin wax. Serial sections of 7 microns thick were obtained using a rotatory microtome. The deparaffused sections were stained routinely with haematoxylin and eosin. ${ }^{9}$ Photomicrographs of the results were obtained using research photographic microscope.

(C) CMS UNIBEN JMBR 2005; 4(1): 83-87 


\section{RESULTS}

The inferior colliculus of the control group showed normal histological features with the neurons appearing distinct with conspicuous cellular population (packed cell population). The neuronal and glia cells appeared normal. There were no vacuolations in the stroma of the sections (Figure 1).

The inferior colliculus of the treated group revealed some cellular degenerative changes such as hypertrophy and sparse cellular population. The stroma showed some vacuolations in the treated sections of the inferior colliculus (Figure 2).

\section{DISCUSSION}

The results showed decreased cellular population, degenerative changes and vacuolations in the treatment group, compared to the more pronounced inferior colliculus of the control section.

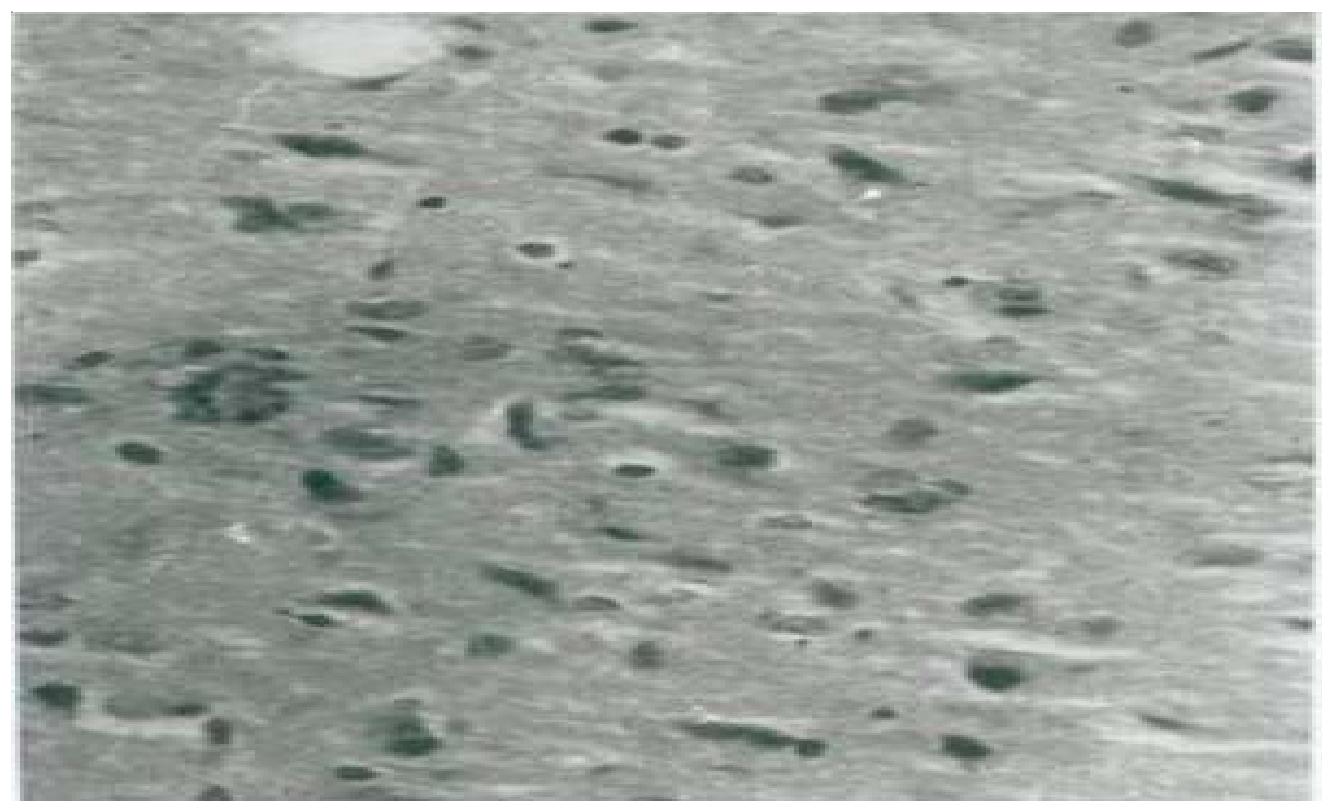

Figure 1 Photomicrograph of the inferior colliculus (control section) (H\&E method x400)

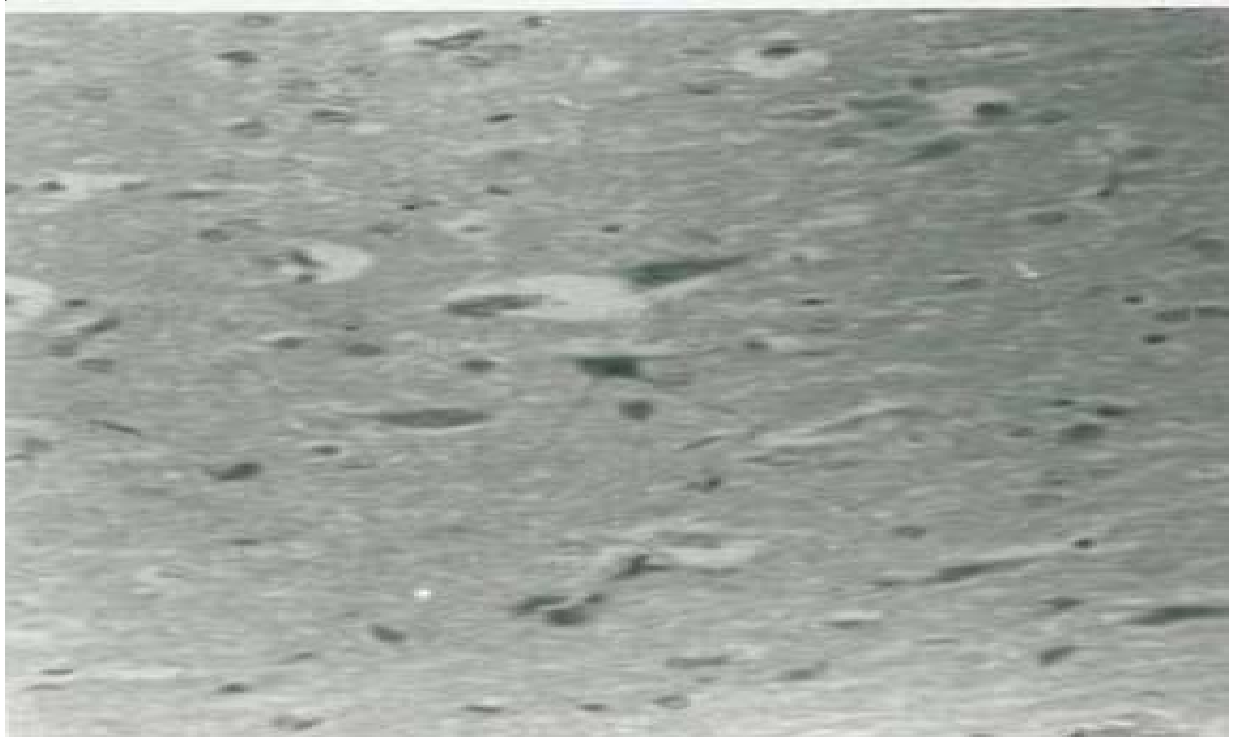

Figure 2 Photomicrograph of the inferior colliculus (treatment section) (H\&E method $\mathrm{x} 400$ ) 
Neuronal degeneration has been reported to result in two types of cell death, namely, apoptotic and necrotic cell death. These two types differ morphologically and biochemically. ${ }^{10}$ Pathological or accidental cell death is regarded as necrotic and could result from extrinsic insults to the cell, such as osmotic, thermal, toxic and traumatic effects. ${ }^{11}$ Physiological cell death is regarded as apoptotic and it's an organised programmed cell death (PCD) that is mediated by active and intrinsic mechanism. Reports have indicated that cell death in response to neurotoxins may trigger an apoptotic death pathway within brain cells. ${ }^{12}$ Cell death in response to neurotoxins occurs as a controlled event involving a genetic programme in which caspase enzymes are activated. ${ }^{12}$

The process of cellular necrosis involves disruption of the membrane's structural and functional integrity. This results in rapid influx of calcium in water and subsequent dissolution of the cell. Cellular necrosis is not induced by stimuli intrinsic to the cells as in programmed cell death (PCD), but by an abrupt environmental perturbation and departure from the normal physiological conditions. ${ }^{13}$ There is a need to further investigate the actual mechanism by which chloroquine phosphate induced neuronal degeneration in the inferior colliculus in rats in this study.

Extensive cell death in the central nervous system is present in all neurodegenerative diseases. ${ }^{12}$ The type of nerve cell lost and the particular part of the brain affected dictate the symptoms associated with an individual disease. $^{12}$

In this study, chloroquine phosphate could have acted as toxins to the cells of the inferior colliculus, affecting their cellular integrity and causing a defect in membrane permeability and cell volume homeostasis. Chloroquine is known to cross membranes by simple diffusion, thus getting access to the cells. ${ }^{14}$ This property of chloroquine could have been one of the causes of the degenerative changes observed in this study. In cellular necrosis, the rate of progression depends on the severity of environmental insults. The greater the severity of insults, the more rapid the progression of neuronal injuries. ${ }^{15}$ The principle holds true for toxic logical insults to the brain and other organs. ${ }^{13}$ The prime candidates for inducing the massive cell destruction observed in neurodegeneration are neurotoxins. ${ }^{12}$ These may be substances present in small amounts in the environment, or even naturally occurring chemicals such as glutamate used by the brain as transmitter substances. ${ }^{12}$ The latter, when present at a critical level, can be toxic to the brain cells they normally excite. ${ }^{12}$ It may be inferred from the present results that prolonged administration of chloroquine resulted in increased toxic effects on the inferior colliculus.

The decrease in neuronal density of the treatment group as reported in this study may have been as a result of cell death caused by the toxic effect of chloroquine. The degenerative processes caused by chloroquine have been reported to lead to the formation of dense bodies, myelin figures and electron dense whorls in nervous tissues. ${ }^{3-5}$

The vacuolations observed in the stroma of the treatment group may be due to chloroquine interference with lipid metabolism. The presence of granular materials that were dissolved by paraffin embedding following chloroquine intoxications in miniature pigs have also been reported. ${ }^{3}$ Chloroquine intoxication has also been reported to result in the accumulation of lysosomal membranes rich in phospholipids and gangliosides due to the inhibition of lysosomal enzymes. ${ }^{16}$

The adverse effects of chloroquine on the inferior colliculus observed in this study may underlie the possible neurologic symptoms, such as tinnitus, as previously reported, ${ }^{1}$ following chloroquine treatment. Chloroquine has also been shown to cause damage to the nervous system (brain and spinal cord) of fetus, including damage to hearing, sense of balance, bleeding inside the eyes and other eye problems in animal studies. ${ }^{17}$ 


\section{CONCLUSION}

Our study revealed that chronic administration of chloroquine causes cellular degenerative changes, hypertrophy and sparse cellular density in the inferior colliculus, and showed some vacuolations in the treated sections of the inferior colliculus. These results indicate that the functions of the inferior colliculus may be adversely affected.

\section{References}

1. Manolette Rangel Roque. Chloroquine/ Hydroxychloroquine toxicity. e-Medicine Journal 2001; 2(5).

2. Adelusi SA and Salako LA. Tissue and blood concentration of chloroquine following chronic administration in the rats. J Pharm Pharmacol 1982; 34: 733-735.

3. Klinghardt GW, Freedman P and Svenerhol L. Chloroquine intoxication induces gangliosides storage in nervous tissues. A chemical and histopathological study of brain, spinal cord, dorsal root ganglia and retina in miniature pig. $J$ Neurochem 1981; 37(4): 897-908.

4. Hodkingson JB and Helga K. A preliminary study of the effect of chloroquine on the rat retina. Arch Ophthalmol 1970; 84: 509-516.

5. Rosenthal AR, Helga K, Donald B, Huxsoll $\mathrm{D}$ and Hopkins JC. Chloroquine retinopathy in the rhesus monkey. Invest Ophthalmol Visual Sci 1978; 17(12): 1158-75.

6. Fall. Mammalian neuroanatomy MCB 163, 1999.

7. Siesjo BK. Utilization of substrates by brain tissues. In: Brain Energy Metabolism. USA: John Wiley and Sons, 1978; 101-130.

8. Benzi G, Dagani AP, Martzatico F, Curti D, Manziri A and Villa RF. Effects of chronic treatment with some drugs on the enzymatic activities of the rat brain. Biochem Pharmacol 1979; 28: 2703-08.

9. Drury RAB, Wallington EA and Cameron R. Carleton's Histological Techniques. Fourth edition. New York: Oxford University Press, 1967; 279-280.

10. Wyllie AH. Glucocorticoid induced thymocyte apoptosis in associated and endogenous endonuclease activation. Nature 1900; 284: 555-556.

11. Farber JL, Chein KR and Mittnacht S. The pathogenesis of irreversible cell injury in ischemia. Am J Pathol 1981; 102: 271-281.

12. Waters CM. Glutamate induced apoptosis of striatal cells in rodent model for Parkinsonism. Neuroscience 1994; 63: 1-5.

13. Martins LJ, Al-Abdulla NA, Kirsh JR, Sieber FE and Portera-Cailliau C. Neurodegeneration in excitoxicity, global cerebral ischemia and target deprivation. A perspective on the contributions of apoptosis and necrosis. Brain Res Bull 1978; 46(4): 281309.

14. Lullman H, Lullman Rauch $\mathrm{R}$ and Wassermann O. Lipidosis induced by amphiphilic cationic drugs. J Biochem Pharmacol 1978; 27: 1103-07.

15. Ito U, Sparts M, Walker JR and Warzo. Experimental cerebral ischemia in magolian Gerbils (1). Light microscope observations. Acta Neurophatol 1975; 32: 209-223.

16. DeGroot PG, Elferink RO, Mariastruland A, Westeveld A, Khan PM and Tager JM. Inactivation by chloroquine of $\alpha$-galacto-sidase in cultured human skin fibroblasts. Exper Cell Res 1981; 136: 327-333.

17. Macromedex. Full disclaimer e-medicine journal. Neuroanatomy 2001; 2(5). 